\title{
GEOGRAFIAS DA EDUCAÇÃO SUPERIOR EM DUAS ESCALAS DE ANÁLISE: A EXPANSÃO DAS UNIVERSIDADES FEDERAIS NO BRASIL E OS IMPACTOS NO ESPAÇO URBANO EM CIDADES MÉDIAS E PEQUENAS DA BAHIA
}

\author{
Geographies of higher education in two analytical scales: the expansion \\ of federal universities in Brazil and the impacts on the urban space in \\ medium and small-sized cities in Bahia
}

\author{
Wendel Henrique Baumgartner* \\ * Professor do Departamento de Geografia Universidade Federal da Bahia (UFBA) \\ - wendelh@ufba.br
}

Recebido em 08/10/2020. Aceito para publicação em 08/06/2021.

Versão online publicada em 09/08/2021 (http://seer.ufrgs.br/paraonde)

Como citar este artigo: BAUMHARTNER, W. H. Geografia da educação superior em duas escalas de anélise: a expansão das universidades federais no Brasil e os impactos no espaço urbano em cidades médias e équenas da Bahia. Para Onde!?, v. X, n. X, p. 35-56, 2021.

\begin{abstract}
Resumo:
Esse texto busca analisar os resultados espaciais, em duas escalas geográficas distintas, da expansão que as universidades federais brasileiras apresentaram, em todo território nacional, nas últimas duas décadas, e destacamos o processo de interiorização em direção às cidades médias e pequenas da Bahia. É importante destacar que, entre meados dos anos 2000 e o início dos anos 2010, é promissor e acelerado o crescimento do número de universidades federais. Infelizmente, os últimos anos representam o oposto, com estagnação, incertezas e possíveis recuos nesse processo. A expansão das instalações das universidades federais em direção as cidades médias e pequenas do Brasil contribuem não apenas para a melhoria no acesso ao ensino superior, mas também trazem impactos no espaço intraurbano das cidades que passam a sediar seus campi, em razão da dinamização econômica, política e cultural trazida pelas instituições. Tanto em áreas economicamente decadentes quanto naquelas de forte dinamismo industrial ou do agronegócio, esses novos campi visam também o desenvolvimento urbano e regional, a partir de aspectos ligados ao que se pode configurar como economia do conhecimento ou economia criativa. Nessa pesquisa que se encerra, foram feitos levantamentos de dados estatísticos, mapeamentos, trabalhos de campo, entre outros. Aqui submetemos algumas análises finais sobre o estudo da geografia da educação superior vinculada a espacialização e periodização da expansão das Universidades Federais no Brasil e buscamos analisar, dialeticamente, impactos decorrentes da instalação dos campi no espaço intraurbano e os aportes econômicos potenciais diretos que as universidades realizam em cidades médias e pequenas da Bahia.
\end{abstract}

Palavras-chave: Expansão universidades federais. Cidades médias. Cidades pequenas. Geografia da educação superior. 


\begin{abstract}
:
This text seeks to analyze the spatial results, in two different geographical scales, of the expansion that Brazilian federal universities have presented along the national territory in the last two decades, stressing the interiorization process, towards to medium and small-sized cities of Bahia State. It is important to highlight that, between the mid-2000s and the beginning of the 2010s, the growth in the number of federal universities is promising and accelerated. Unfortunately, the last few years represent the opposite, with stagnation, uncertainty, and possible obstructions in this process. The expansion of federal university facilities towards medium and small cities in Brazil does not only contribute to improving access to higher education, but also impacts the intra-urban space of cities that host their campuses, due to the dynamization of economic, political, and cultural aspects. Both in economically decadent areas and in those with strong industrial dynamism or agribusiness production, these new campuses also aim urban and regional development, based on aspects related with knowledge economy or creative economy. In this research, that ends, we collected statistical and qualitative data, mapping and fieldworks took place, among other methodologies. Here, we submit some final analyzes on the study of the geography of higher education linked to the spatialization and periodization of the expansion of Federal Universities in Brazil and we seek to analyze, dialectically, some impacts resulting from the campus installation and the potential direct economic apport of capital, promoted by the universities in medium and small-sized cities located in Bahia state.
\end{abstract}

Keywords: Expansion of federal universities. Medium cities. Small towns. Geography of higher education.

\title{
1. Introdução
}

A década relacionada aos anos 2010 possui um duplo significado para o processo de expansão e interiorização das universidades federais brasileiras. Apesar de se iniciar com um período de intensa expansão dessas instituições de ensino superior em direção às cidades médias e pequenas do Brasil, com criação de universidades federais completamente novas ou com a instalação de campi avançados de universidades já existentes e consolidadas, os anos finais da década representam exatamente o oposto. As mudanças na orientação política e nos projetos educacionais do Ministério da Educação impactaram fortemente o processo de expansão, com a paralização do mesmo e ampliação de incertezas, como acerca da viabilidade dos novos campi e instituições devido aos cortes orçamentários.

O período de expansão vigorosa das universidades federais, relacionado ao Programa de Apoio a Planos de Reestruturação e Expansão das Universidades Federais (REUNI). O Programa de Apoio a Planos de Reestruturação e Expansão das Universidades Federais (REUNI), foi uma política pública (BRASIL, 2007), idealizada e executada pelo Ministério da Educação (MEC), entre os anos de 2007 e 2012. Dentre inúmeras críticas a essa política, entre elas a da precarização do trabalho do docente e a imposição/aceite de suas orientações produzidas sem participação na estrutura das Universidades, o REUNI propiciou uma grande expansão na cobertura geográfica das Universidades Federais, ampliando significativamente tanto o número de instituições quanto o de municípios atendidos pelo Sistema Federal de Ensino Superior. 
Além do significativo impacto no acesso ao ensino superior, essa expansão apresentou uma dimensão de desenvolvimento econômico, visível nos espaços regionais e intraurbano em razão do forte impacto econômico, político e cultural trazido pelos campi dessas universidades. Tanto em áreas economicamente estagnadas quanto naquelas de forte dinamismo industrial ou do agronegócio, esses novos campi visam também o desenvolvimento urbano e regional, a partir de aspectos ligados ao que se pode configurar como economia do conhecimento ou criativa.

Nesse artigo apresentamos algumas discussões finais no âmbito de uma pesquisa de longa duração, financiada pela Coordenação de Aperfeiçoamento de Pessoal de Nível Superior (Capes), Conselho Nacional de Desenvolvimento Científico e Tecnológico (CNPq) e Fundação de Amparo à Pesquisa do Estado da Bahia (FAPESB), entre os anos de 2006 e 2018, para acompanhar a expansão do Sistema Federal de Ensino Superior, focando em primeiro momento a Bahia, mas posteriormente ampliando o espaço de pesquisa para outros estados brasileiros, bem como realizando estudos sobre a temática em outros países (DEMAZIÉRE \& BAUMGARTNER, 2017). No que concerne a base empírica da pesquisa, especificamente nesse texto, traremos reflexões sobre a espacialização dos campi das universidades federais em duas escalas distintas. Na escala geográfica ampla, abordaremos o território nacional, espacializando a expansão na base municipal brasileira. A apresentação dos dados para o país permite compreender a totalidade do processo de expansão. Em um segundo momento, o trabalho trata em escalas geográfica menores, através de estudos empíricos mais detalhados, da expansão no estado da Bahia, focando a análise em nas cidades médias e pequenas de Cachoeira, Cruz das Almas, Santo Antônio de Jesus e Barreiras. Dessa forma, podemos apresentar tanto a situação, em nível nacional do processo de expansão das universidades federais, quanto tratar de particularidades e singularidades no mesmo processo no estado e cidades baianas.

O levantamento de dados referentes à possíveis novas universidades criadas entre a finalização da pesquisa, em dezembro de 2018, e outubro de 2020, bem como a leitura das novas diretrizes políticas do Ministério da Educação, partiu de uma inquietação acadêmica sobre a expansão/estagnação do Sistema Federal de Ensino Superior, durante os meses de fechamento físico das universidades, em razão da pandemia do covid-19. A emergência sanitária ratificou a importância da pesquisa científica e das universidades na produção e difusão do conhecimento.

Além desse aspecto, a compreensão do papel das universidades como agentes da (re)estruturação econômica das cidades torna-se importante, tanto em razão do volume de recursos financeiros movimentados quanto pela modificação de dinâmicas intraurbanas (moradia, circulação, usos etc.) e do cotidiano dos moradores (BAUMGARTNER, 2015a). Assim, a implantação de um campus de uma universidade pública afeta as dinâmicas urbanas e regionais das cidades, dentro de uma estratégia governamental de promoção do desenvolvimento urbano e regional que, para além do impacto econômico direto através da geração de empregos públicos de alta qualificação e gastos básicos de alunos e professores, promove a melhoria dos padrões educacionais, qualificação da força de trabalho, avanço e desenvolvimento tecnológico e cultural. As universidades contribuem para o desenvolvimento (econômico, político e cultural) urbano e regional, dinamizando 
cidades, suas bases econômicas, sua morfologia e mesmo suas imagens na rede urbana, agora mundializada.

Devido as restrições de circulação, necessárias para a contenção do avanço do vírus, não realizamos trabalhos de campo para coletar informações in loco, sobre o impacto econômico da passagem das atividades presenciais para o ambiente online, bem como do período de lockdown enfrentado pela população e o fechando temporário de muitas universidades. Essa discussão é um campo aberto para futuras pesquisas.

\section{Teorias e conceitos}

Dentre as múltiplas possibilidades de análise, empregamos nesse estudo sobre a expansão das universidades federais brasileiras para as cidades médias, a perspectiva de influência da educação superior na denominada 'era da economia do conhecimento e criativa'.

Segundo Cassiolato (1999), a ideia de economia do conhecimento, ou economia baseada no conhecimento, deriva do desenvolvimento de novos processos produtivos fundados mais na aplicação e desenvolvimento de novas tecnologias, aplicações e design de produtos, do que no produto propriamente dito. Assim, ocorre uma expansão e intensificação do uso do conhecimento 'mais avançado' em diversos setores produtivos, dos mais tradicionais (indústria metalomecânica, química, entre outros) aos mais contemporâneos (eletrônicos, informática etc.), passando por setores como produção cultural, publicidade, entre outros. Para atender essa demanda econômica por conhecimento, as universidades atuam muitas vezes em parceria com setores produtivos, para o desenvolvimento de conhecimento básico e aplicado para essa demanda. Essa não é uma associação nova, basta nos lembrarmos das universidades/institutos tecnológicos alemães criados no século XIX, como suporte para o processo de industrialização daquele país. No período contemporâneo, definido por Milton Santos (1997) como técnicocientífico-informacional, observa-se um avanço dessa relação entre as universidades, a produção e difusão do conhecimento para fins de desenvolvimento econômico, o que acaba por transformar o conhecimento e a criatividade em uma 'commodity'.

Ainda de acordo com Cassiolato (1999), a produção do conhecimento conecta as redes ou sistemas oficiais (públicos/privados) de educação, em especial as universidades; a estrutura de institutos de pesquisa, com destaque para aqueles que se dedicam ao desenvolvimento tecnológico; as redes e os meios de comunicação e informação; as estruturas de pesquisa e desenvolvimento das empresas e indústrias; e as políticas públicas no âmbito da ciência e da tecnologia.

Nos Estados Unidos, Zecher (2005) coloca que as políticas tradicionais de desenvolvimento econômico em cidades médias se baseiam em incentivos fiscais e de localização. Esse modelo se mostrou falho e propiciou a estagnação econômica de várias cidades, com declínio da atividade industrial, perda de empregos e baixa competitividade. A solução para essa questão seria a passagem de uma economia baseada em modelos tradicionais de produção e incentivo para um modelo de economia criativa e de inovação, implicando a melhoria da qualificação profissional e 
de infraestrutura, desenvolvendo a economia do conhecimento. Esse salto qualitativo só é alcançado através do impacto positivo das universidades e dos institutos de pesquisa tecnológica, que possuem força para serem agentes desencadeadores e promotores da economia do conhecimento, tanto em nível local quanto regional.

A expansão de instituições de ensino superior no Brasil pode ser compreendida como uma política de Estado que visa dotar o território de equipamentos necessários para a participação nas atividades produtivas mais avançadas. Uma das demandas produtivas colocadas por setores produtivos e que a expansão das universidades, institutos tecnológicos ou centros de pesquisa e desenvolvimento, tenta resolver está no campo, através do melhoramento de sementes, pesquisas com animais, suporte para ampliação dos complexos agroindústrias, entre outro. Assim, uma parcela das universidades no interior do Brasil acaba por se 'especializar' em cursos voltados para a produção de conhecimento 'agropecuário' e desenvolvimento do agronegócio.

Dessa forma, se em outros momentos do desenvolvimento tecnológico, o acesso à informação e, principalmente, de contato com o mundo era privilégio das universidades localizadas em grandes centros, hoje com a expansão das redes de informação (fibras óticas e satélites), autoestradas e aeroportos, esta diferenciação na dotação de infraestruturas de transporte e comunicação foram diluídas. É claro que não foram completamente superadas, pois geralmente 0 tempo de deslocamento e as conexões, quando tratamos de transporte aéreo, por exemplo, é maior para aqueles que têm como ponto de origem e/ou destino cidades menores.

A atração de uma universidade e a definição da gama de cursos a serem ofertados é também espaço de uma intensa batalha política, nos mais diversos níveis. $O$ anúncio de um projeto de expansão de uma universidade e a construção de um campus geram, por parte dos políticos locais e regionais uma intensa associação com elites empresariais, com a comunidade artística e acadêmica, para que o município de sua base eleitoral receba a instituição. Essa movimentação política leva até a redefinição da espacialização de campus, conforme observado na Bahia, onde o campus de Nazaré da Universidade Federal do Recôncavo da Bahia (UFRB) foi revogado no projeto inicial para dar origem, após intensa pressão política e artística, aos campi de Cachoeira e Santo Amaro, da referida universidade. $O$ significado político e a capitalização da atração de uma universidade pela classe política são facilmente observados durante as campanhas eleitorais, associando a nova instituição a uma melhoria na imagem e na economia do município ou região.

Para Claval (1998) as universidades melhoram, de maneira geral, a atração de serviços e novas atividades para o centro urbano, incentivando a vinda de executivos ou técnicos para as cidades médias e pequenas, seduzidos também pela proximidade de educação superior de qualidade nas localidades. Muitas dessas cidades, através da presença de uma universidade, buscam sua inserção na rede urbana como um polo tecnológico, facilitando a atração de atividades de alta tecnologia.

Nesse ponto, podemos fazer outra associação entre as universidades e as cidades, através de conceitos como economia criativa ou cidade de inovação. A economia criativa é aquela produzida por setores como arquitetura, artes, cinema,

Para0nde!?, Porto Alegre, v.15, n.1, p.35-56, 2021. http://seer.ufrgs.br/paraonde 
publicidade, música, mídia, comunicação, informações, entre outros. Richard Florida (2002 e 2005) apresenta diversos estudos sobre o papel da economia criativa e das cidades criativas (ou inovadoras), em também fortalece o papel das universidades tanto na criação de produtos/ideias inovadoras quanto na produção de um ambiente criativo, conforme destacado por Baumgartner \& Rothfuss (2017), e um fortalecimento da imagem das cidades universitárias perante as demais cidades. Em 2015, de acordo com o índice de criatividade (FLORIDA et al, 2015), o Brasil ocupava a 29a posição no ranking global de criatividade, mas a $28^{a}$ considerando investimentos em pesquisa e desenvolvimento; a $27^{\text {a }}$ em desenvolvimento de tecnologias globais; a $61^{\underline{a}}$ em empregos na área criativa (ciência, tecnologia, engenharia, artes, cultura, entretenimento, mídia e educação) e a 68a considerando o nível educacional da classe criativa. Já em relação ao índice de inovação (WIPO/ONU, 2011 e 2019), o Brasil caiu da posição 47ª em 2011 para a 66 em $^{\text {a }}$ 2019.

Infelizmente, observamos nas universidades brasileiras, novas ou antigas, um número relativamente pequeno de cursos voltados para a criatividade e artes, com exceção aos cursos publicidade e arquitetura. Essa discussão será retomada na seção 4 desse artigo, quando apresentarmos informações mais específicas sobre os cursos de graduação relacionados ao setor criativo na área de estudo na Bahia. No processo de expansão das universidades é preciso olhar com cuidado para a questão dos cursos, pois o que foi observado é uma pressão política para o recebimento dos campi e uma predileção por cursos 'tradicionais de prestígio', como direito, administração ou medicina, deixando pouco espaço para cursos com 'menor' prestígio, mas com grande impacto economia criativa.

\section{Método e notas metodológicas}

Apesar da opção por trazer uma espacialização da geografia da educação superior, produzida pelas Universidades Federais brasileiras, construída através de levantamento de dados estatísticos, o método que guia a pesquisa, desde sua concepção e desenvolvimento até as análises finais, é dialético. Através da dialética busca-se construir tanto uma periodização do processo de expansão quanto uma discussão sobre as contradições e potencialidades transformadoras da presença de um campus universitário em uma cidade ou região, desde o ponto de vista espacial até o estrutural.

Metodologicamente, a pesquisa que embasa a discussão trazida nesse texto possui um duplo fundamento, tanto em aspectos quantitativos quanto qualitativos. Cabe indicar que a descrição completa dos procedimentos metodológicos da pesquisa completa, que vai além do que é exposto nesse artigo, pode ser consultada em Baumgartner (2015b e 2019). A base quantitativa nacional, usada para a periodização e produção de um mapa síntese da expansão das universidades federais, está relacionada ao levantamento de dados oficiais, produzidos pelo Ministério da Educação, disponibilizados na Plataforma E-Mec (emec.mec.gov.br). Há também dados disponíveis sobre o Sistema Federal de Ensino Superior (SFES) no Portal do SINAES - Sistema Nacional de Avaliação da Educação Superior (http://sinaes.inep.gov.br:8080/sinaes). As informações são públicas. Os dados são públicos e de consulta aberta. Os dados levantados foram tabulados e 
espacializados usando-se uma base municipal do território brasileiro, através do software de geoprocessamento ArcGIS.

$\mathrm{Na}$ escala municipal, para as localidades do estudo na Bahia (Barreiras, Cachoeira, Cruz das Almas e Santo Antonio de Jesus), a partir da consulta aos dados censitários e por amostragem, produzidos pelo Instituto Brasileiro de Geografia e Estatística (IBGE) e pela Superintendência de Estudos Econômicos e Sociais da Bahia (SEI), foram sistematizadas informações referentes à população e seus indicadores econômicos e sociais, bem como números referentes aos orçamentos municipais, IDH (Índice de Desenvolvimento Humano) e evolução dos empregos formais. A utilização desses dados visa identificar a intensidade do impacto da instalação da universidade nas cidades.

Especificamente sobre as Universidades Federais, nesse artigo, buscamos apresentar os dados mais recentes disponibilizados pelas duas universidades que estudamos com maior detalhe na Bahia, com relação ao número de estudantes, servidores e professores, o que permite um cálculo mais atualizado dos recursos potencialmente investimentos pelas universidades nas cidades (Barreiras, Cachoeira, Cruz das Almas e Santo Antonio de Jesus), destacando o aporte direto através do pagamento de salários e, indiretos, decorrente dos gastos de manutenção do corpo discente.

\section{Espacialização da expansão das Universidades Federais no Brasil e estudos empíricos na Bahia}

Desde a segunda metade dos anos 2000 observamos uma forte expansão do Sistema Federal de Ensino Superior (Universidades e Institutos Tecnológicos) vinculadas e mantidas pelo Ministério da Educação (HENRIQUE, 2009; 2012; 2013; BAUMGARTNER, 2014). Em vários estados brasileiros essa expansão se direciona para cidades médias e pequenas do interior, após um grande período de concentração de instituições federais apenas nas capitais.

Essa expansão recente é uma política de Estado adotada no país em meados dos anos 2000, associada ao REUNI (BRASIL, 2007), através da criação e instalação de novas universidades e institutos federais ou campi avançados de instituições federais já existentes. Dos anos 1990 até o início dos anos 2000, as políticas locacionais/territoriais das instituições de nível superior atribuíam as empresas privadas a abertura e manutenção de faculdades e universidades no país.

Além de um novo momento de ação direta do Estado na expansão das instituições públicas de ensino superior para cidades médias e pequenas, também se constata um rápido avanço na criação de polos que dão suporte para os cursos na modalidade de Ensino à Distância (EAD). Este processo se complementa com os campi das instituições privadas e estaduais, destinadas ao ensino presencial, mas que não se expandiram, neste período, com a mesma intensidade daquela registrada pelos dois grupos citados inicialmente.

Mostraremos uma geografia do ensino superior, baseada na localização e expansão das universidades federais no Brasil, usando uma base municipal e retratando apenas os campi que oferecem ou ofereceram cursos de graduação presenciais. Não estão mapeados os dados referentes aos institutos federais. Os 
dados são do sistema de registro dos cursos de graduação, disponíveis na Plataforma E-Mec (emec.gov.br) e cabe destacar que alguns municípios mapeados tiveram cursos presenciais temporários, vinculados as instituições federais. Essa base de dados, mesmo sendo elaborada pelo próprio Ministério da Educação, apresenta algumas lacunas, principalmente em relação ao período de funcionamento de cursos temporários e aos cursos que foram extintos.

Apesar do foco do trabalho estar na análise mais recente do processo de expansão, tanto a periodização quanto o mapa síntese (Figura 01), se referem a temporalidades pretéritas, que se iniciam com o estabelecimento da primeira instituição governamental de ensino superior no Brasil, em 1808, e perpassam outros momentos da história de criação de universidade atreladas ao governo federal, até chegarmos, no período atual. A data de 1808, além de ser um marco histórico, é importante para, inclusive, compreendermos quão tardiamente recebemos uma instituição de ensino superior no Brasil, em comparação com outros países na América Latina. A Universidade Santo Tomás de Aquino/Universidade Autónoma de Santo Domingo, em Santo Domingo/República Dominicana foi fundada em 1538 (é a primeira universidade das Américas); a Universidade Nacional de San Marcos, em Lima/Peru, foi criada em 1551; mesmo ano de fundação da Real e Pontifícia Universidade de México/Universidade Nacional Autônoma do México, na Cidade do México. Na Argentina, a primeira universidade é de 1613 - Universidade Nacional de Córdoba, localizada em Córdoba.

Cabe destacar, que elaboramos a periodização, agrupando períodos de tempos com durações distintas, conforme preconiza o método dialético, mas que possuem uma coerência interna, definida por uma componente estrutural ou política. Sobre o mapa síntese, é importante destacar que é basicamente o mesmo desde 2015, uma vez que as instituições mais novas são desmembramentos de antigos campi de universidades já consolidadas. Dessa forma, as novas universidades não alteram a presença das instituições por municípios.

\section{- $\quad$ Período 01. 1808 até 1955}

Esse período inicial é marcado pelas primeiras instituições ligadas ao poder central no estabelecimento de cursos de ensino superior, para além das instituições de cunho religioso que já ofertavam cursos de teologia e filosofia. Na virada para o século XX, apenas quatro cidades brasileiras tinham cursos superiores financiados pelo poder central: Salvador, Recife, São Paulo e Rio de Janeiro. Nos anos 30 começa uma primeira onda de expansão, com a criação de universidades nas capitais dos estados e no interior de duas unidades da federação: Rio Grande do Sul e Minas Gerais.

\section{- $\quad$ Período 02. 1956 - 1970}

O segundo período é marcado por uma pequena expansão da rede do Sistema Federal, a partir de Uberlândia em direção ao Centro-Oeste. Também destacamos a criação da Universidade Federal de São Carlos (Ufscar), em São Paulo, onde o sistema de universidades estaduais já se interiorizava com a criação da Universidade Estadual de Campinas (Unicamp) e a Universidade Estadual Paulista (Unesp), sendo essa última com estrutura de múltiplos campi;

- $\quad$ Período 03. 1971 - 1985

Para0nde!?, Porto Alegre, v.15, n.1, p.35-56, 2021. http://seer.ufrgs.br/paraonde 
O terceiro período reforça a expansão da rede no Centro-Oeste e avança, junto a expansão da fronteira agrícola, para o Norte. Em outros estados também são criados diversos campi avançados, de instituições já existentes, destinados às áreas de ciências agrárias.

\section{- $\quad$ Período 04. 1986 - 2002}

O quarto período, que marca o início da redemocratização do país, é claramente marcado pelo reforço da rede federal no Norte do país, com destaque para o Pará e Amapá, bem como no estado de Tocantins.

- $\quad$ Período 05. $2003-2010$

Esse é o período mais forte e balanceado da expansão do Sistema Federal de Ensino Superior. Observamos que todos os estados, em todas as regiões, receberam campi de instituições federais existentes ou novas. A expansão toma lugar efetivo no interior do país, nas cidades médias e pequenas. Muitos campi são criados em áreas mais pobres e menos desenvolvidas, do ponto de vista econômico.

O modelo multi-campi é o marco dessa etapa, bem como a contemplação de uma perspectiva mais regional na atuação das universidades, inclusive na nomenclatura: Universidade dos Vales do Jequitinhonha e Mucuri, do São Francisco, dos Pampas, da Fronteira Sul, entre outras.

Também destacamos as universidades com uma vocação internacional, como a Universidade Federal da Integração Latino-Americana (UNILA) e Universidade da Integração Internacional da Lusofonia Afro-Brasileira (UNILAB).

- $\quad$ Período 06. $2011-2016$

O período mostra o último momento de expansão geográfica da cobertura de municípios brasileiros. Ainda que menos acelerada, em relação ao período anterior, as novas unidades e campi são criados em novos municípios, ampliando a Rede Federal. O destaque é a criação de universidades novas na área do cerrado. As novas instituições também seguem a estrutura multi-campi e se localizam, de maneira geral, em áreas dinâmicas das economias regionais.

- $\quad$ Período 07. 2016 - 2020

O último, e mais recente, período é marcado pela mudança nas políticas de expansão e ampliação da Rede Federal, de acordo com as novas diretrizes do Ministério da Educação. As mais novas universidades federais brasileiras são:

- Universidade Federal de Jataí (UFJ), com projeto de emancipação da Universidade Federal de Goiás, com criação de uma instituição nova datado de maio de 2016 e sancionado em maio de 2018. A instituição tem sede e atividades localizadas em Jataí/GO;

- $\quad$ Universidade Federal do Agreste de Pernambuco (Ufape), desmembrada em abril de 2018 da Universidade Federal Rural de Pernambuco (Ufrpe). Sua sede fica em Garanhuns/PE;

- $\quad$ Universidade Federal de Rondonópolis (UFR), criada em março de 2018 a partir de projeto de autonomia em relação a Universidade Federal de Mato Grosso. Está localizada em Rondonópolis/MT; 
- Universidade Federal do Delta do Parnaíba (Ufdpar), criada pelo desmembramento do campus Paraíba (projeto de 2016), da Universidade Federal do Piauí, sancionado em 2018. Os cursos funcionam na sede de Parnaíba/PI;

- Universidade Federal de Catalão (Ufcat), constituída em março de 2018 com a emancipação do campus avançado da então Universidade Federal de Goiás. Está localizada no município de Catalão/GO.

Figura 1 - Mapa síntese da localização das Universidades Federais

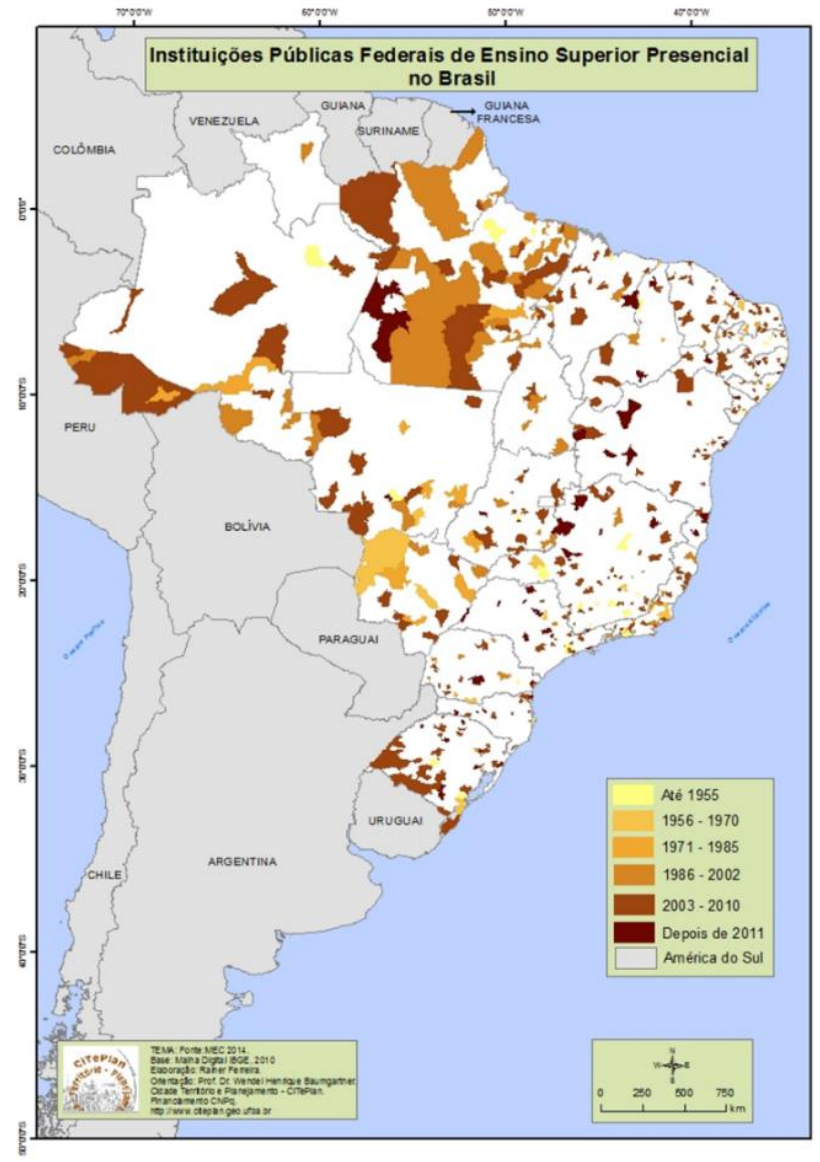

Elaboração: Rainer Ferreira

A leitura dos dados referentes a esse último período, e às novas instituições federais, indica mais um processo de reestruturação administrativa e desmembramento de antigos campi de instituições consolidadas, do que de expansão geográfica. A autonomia dessas novas instituições poderá significar um aumento da oferta de cursos e a criação de novos campi. Entretanto, até o momento, consultando os sites oficiais das referidas universidades não foram encontrados projetos de expansão para outros municípios fora da sede, onde já havia ofertas de cursos vinculados ao sistema federal de ensino superior.

Dessa forma, a geografia do ensino superior, a partir da localização dos campi das universidades federais não se altera, para além da questão organizacional/administrativa.

\subsection{A geografia do ensino superior na Bahia}


Em 1808, Salvador recebeu a primeira instituição pública de ensino superior do Brasil (Faculdade de Medicina da Bahia). De 1808 até 1976, apenas a cidade de Salvador possuía uma instituição pública, vinculada as sucessivas formas de organização do governo brasileiro, no Estado da Bahia. Em 1977, a Universidade Federal da Bahia (UFBA) abriu um campus em Cruz das Almas, uma cidade no interior onde foram implantados os cursos relacionados a agronomia. Entre 2002 e 2010, sete outras cidades receberam campus de instituições federais. Entre 2011 e julho de 2014, nove cidades entraram para esse grupo de cidades. Mais recentemente, cinco novos municípios, sendo quatro no oeste e um norte do estado, receberam campi universitários. Outras cidades baianas possuem campus de instituições estaduais de educação superior. Apesar da expansão, várias áreas do estado ainda estão descobertas e ainda não possuem uma rede federal bem descentralizadas, como nos estados de Minas Gerais e Rio Grande do Sul.

$\mathrm{Na}$ Bahia, assim como nos demais unidades federativas, a expansão das universidades federais se dá na forma de três processos diferentes:

a) Criação de campus relacionado ao projeto de expansão de uma universidade existente (Campus Vitória da Conquista e Camaçari/UFBA);

b) Criação de campus de universidade nova: Universidade do Recôncavo da Bahia (UFRB), em Amargosa, Cachoeira, Cruz das Almas, Feira de Santana, Santo Amaro e Santo Antonio de Jesus; Universidade do Oeste da Bahia (UFOB), nas cidades de Barra, Barreiras, Bom Jesus da Lapa, Luís Eduardo Magalhães e Santa Maria da Vitória; e Universidade do Sul da Bahia (UFSB), em Itabuna, Porto Seguro e Teixeira de Freitas;

c) Criação de campus de universidade nova: Unilab, em São Francisco do Conde; e Universidade do Vale do São Francisco (Univasf) nos municípios baianos de Juazeiro, Senhor do Bonfim e Paulo Afonso.

Todas as situações de expansão suportam diferentes critérios de análise e possíveis diferenças na constituição do campus, quer seja de uma universidade em expansão ou de uma universidade nova, principalmente no tocante a quantidade e tipologia dos cursos a serem oferecidos, o que cria uma demanda diferencial por parte dos docentes e discentes por moradia. Pesquisas indicam que professores vinculados a cursos como medicina e direito geralmente atuam em mais de uma instituição e/ou clínica/escritório; estudantes de cursos de engenharia, medicina e direito tendem a possuir uma renda média maior do que alunos dos cursos de licenciatura. Como as universidades já estabelecidas oferecem os cursos de maior 'status' em seus campi-sede, no momento da expansão buscam criar cursos novos e notadamente licenciaturas. Nas universidades novas são criados cursos de todas as áreas, inclusive estes tradicionalmente preenchidos por estudantes de maior renda.

Em 2005, a expansão da Universidade Federal da Bahia (UFBA) possibilitou a abertura de dois campi avançados da universidade, o Instituto Multidisciplinar de Saúde em Vitória da Conquista e o Instituto de Ciências Ambientais e Desenvolvimento Sustentável (ICADS) em Barreiras. O campus de Barreiras foi criado com mais cursos de graduação e já possuía cursos de pós-graduação quando foi desmembrado da UFBA, dando origem a uma outra universidade, a UFOB (Universidade Federal do Oeste da Bahia). Com a criação da UFOB, outras quatro cidades receberam os campi da universidade: Luís Eduardo Magalhães, Barra, 
Santa Maria da Vitória e Bom Jesus da Lapa.

A Universidade Federal do Recôncavo da Bahia (UFRB) foi criada em 2005, a partir do desmembramento de uma unidade da UFBA localizada em Cruz das Almas. Sua instalação ocorreu em 2006 e a universidade possui uma constituição multicampi, localizada inicialmente em 04 municípios baianos: Cachoeira, Cruz das Almas (Reitoria), Amargosa e Santo Antônio de Jesus. Em 2014 foram implantados mais dois campi da UFRB, em Santo Amaro e Feira de Santana.

A mais recente instituição com sede no estado da Bahia é a UFSB Universidade Federal do Sul da Bahia, que possui campi instalados em de Teixeira de Freitas, Porto Seguro e Itabuna (Reitoria), além de contar com unidades auxiliares em diversos outros municípios do sul da Bahia, atendendo a um desenho curricular e institucional mais descentralizado que as demais instituições. Os cursos oferecidos também se distinguem dos mais, como as Licenciaturas Interdisciplinares.

A Universidade do Vale do São Francisco (Univasf) e a Universidade da Integração da Integração Internacional da Lusofonia Afro-Brasileira (Unilab), que possuem presença em mais de um estado brasileiro. O campus baiano da Unilab está em São Francisco do Conde (Região Metropolitana de Salvador) e a Universidade do Vale do São Francisco (Univasf) está presente nos municípios baianos de Juazeiro, Senhor do Bonfim e Paulo Afonso.

\section{Impactos no espaço intraurbano}

No espaço intraurbano das cidades médias e pequenas, a expansão das universidades federais do SFES, movimenta a produção do espaço, através da ação direta dos diversos agentes (Estado, agentes imobiliários, prestadores de serviços, comerciantes, população nova e moradores antigos) com a dinamização e transformação das economias locais e regionais, bem como da própria estrutura urbana e das cidades. No plano morfológico, que segundo Capel (2002), compreende os elementos básicos que constituem a estrutura material da cidade e é produzido nas esferas sociais, econômicas, políticas e sociais, a (re)estruturação das cidades (Sposito, 2004) está vinculada a expansão da mancha urbana, a construções de conjuntos residenciais para estudantes, a abertura de novas vias de circulação e o adensamento de áreas edificadas, por exemplo. As instituições de ensino superior possuem grandes orçamentos, que muitas vezes são superiores aos dos municípios onde estão instalados. Em meados da década de 2010, ainda antes dos cortes estabelecidos, as universidades federais contavam com orçamentos aprovados de R $\$ 5$ bilhões, ou aproximadamente US $\$ 2,2$ bilhões (de acordo com a média do câmbio real/dólar em 2014).

Em 2019, UFRB e UFOB tinham orçamentos anuais de $R \$ 275,9$ e $R \$ 102,1$ milhões, respectivamente. Esse volume de recursos sofreu um declínio em 2020, passado para $R \$ 265,9$ milhões (UFRB) e $R \$ 96,6$ milhões (UFRB), segundo dados oficiais da Transparência online Plataforma (http://www.portaltransparencia.gov.br). A UFOB possui um orçamento maior do que o orçamento municipal anual, segundo a Plataforma IBGE Cid@des (dados de 2018), de Bom Jesus da Lapa (R\$94,2 milhões); e próximo ao de Santa Maria da Vitória (R\$106,1 milhões). A exceção de Feira de Santana ( $R \$ 1,1$ bilhão), todos os outros cinco municípios com campus da 
UFRB, possuem orçamentos anuais menores do que a universidade: Cachoeira ( $\mathrm{R} \$$ 70,2 milhões); Cruz das Almas (R\$ 109,1 milhões); Santo Antonio de Jesus (R\$ 182,2 milhões); Amargosa ( $\mathrm{R} \$ 63,4$ milhões); e Santo Amaro ( $\mathrm{R} \$ 114,5$ milhões).

Essas cidades receberam grandes investimentos que trouxeram consigo um incremento da migração de pessoas com alta qualificação profissional (professores universitários, pesquisadores, técnicos e administradores, entre outros), bem como estudantes universitários, muitos deles com alto poder aquisitivo, vinculados notadamente a determinados cursos, tais como medicina, odontologia, engenharias e direito entre outros. Os alunos com rendas menores, que não são atendidos pelos programas de moradia estudantil, também provocarão impacto no mercado imobiliário das cidades através da criação das moradias coletivas, denominadas por 'repúblicas'.

É interessante notar, que esse novo perfil de moradores, contrasta com o tipo clássico do morador do interior. Segundo Santos (2005), as pequenas cidades do interior eram cidades dos notáveis, povoadas por personalidades marcantes como o padre, a professora primária e o juiz. Através da ação direta do Estado, em projetos de desenvolvimento que visam não só a modernização da estrutura econômica, mas também urbana e social, algumas cidades acabam por se transformar em cidades econômicas, com a substituição do personalismo pela qualificação profissional. A professora primária sede lugar para a professora universitária, entram em cena a engenheira, o agrônomo, entre outros.

Mas, esses novos perfis de empregos e salários, associados as universidades também tem suas contradições. Em Cachoeira, a renda média mensal per capita nos domicílios urbanos é de $\mathrm{R} \$ 368,12$ (PNUD, 2013). Naquele mesmo ano, o salário inicial de um professor com dedicação exclusiva, que possuísse doutorado, era 25 vezes maior do que a renda média da população local. Essa diferenciação na renda teve um primeiro impacto no mercado imobiliário da cidade, com o aumento expressivo dos valores cobrados para aquisição e aluguel de imóveis. Em 2008 (Henrique, 2009), o valor médio das pequenas casas (com um quarto) alugadas passou de $R \$ 150,00$, antes da chegada da UFRB, para $R \$ 800,00$. Com essa valorização provocada pelo aumento da demanda e pouca oferta, a população local foi forçada a sair das áreas mais centrais da cidade e ocupar espaços periféricos.

Um possível indicador do impacto positivo da instalação das universidades está no Índice de Desenvolvimento Humano dos Municípios (IDH-M), especialmente no quesito Educação (Tabela 1), que indica escolaridade da população adulta e fluxo escolar da população jovem. A presença de uma universidade pública e gratuita, com diversos programas facilitadores de acesso e permanência de estudantes, é um incentivo à busca por melhoria no nível de escolaridade da população local, que não precisaria se deslocar para outros centros, evitando, por exemplo, custos de manutenção com aluguéis. A UFOB possui um programa de bonificação regional para os candidatos que residam em sua área de influência direta $(150 \mathrm{~km}$ em torno de seus cinco campi), cujo objetivo é aumentar a proporção de estudantes locais nos cursos de graduação. Isso ajuda a aumentar o nível de escolaridade e o tempo de permanência nas instituições públicas de ensino nessas cidades médias e pequenas. 
Tabela 1 - IDH municipal geral e em educação

\begin{tabular}{ccccc}
\hline \multirow{2}{*}{ Município } & \multicolumn{2}{c}{$\mathrm{IDH}^{\mathrm{ID}} \mathrm{M}^{*} 2000$} & \multicolumn{2}{c}{$\mathrm{IDH}-\mathrm{M}^{*} 2010$} \\
& Geral & Educação & Geral & Educação \\
\hline Barreiras & 0.572 & 0.414 & 0.721 & 0.668 \\
Cachoeira & 0.516 & 0.372 & 0.647 & 0.577 \\
Cruz das Almas & 0.574 & 0.452 & 0.699 & 0.650 \\
Santo Antonio de Jesus & 0.560 & 0.401 & 0.622 & 0.700 \\
\hline
\end{tabular}

Fonte: Atlas do Desenvolvimento Humano no Brasil. Disponível em: atlasbrasil.org.br/ranking, acessado em 29/01/2021.

* Escala IDH: 0,800 - 1.000 (muito alta); 0,700 - 0,799 (alto); 0,600-0,699 (média); 0,500 - 0,599 (baixo); 0,000 - 0,499 (muito baixo).

Em diversas cidades, o empreendedorismo, as startups também se tornam palavras recorrentes no mercado de trabalho e na vida econômica, atreladas a economia do conhecimento. Professores e ex-estudantes criam empresas, comércios e serviços; estudantes implementam empresas-júnior; universidades se associam ao setor industrial na estratégia de incubar e desenvolver novos produtos. Para exemplificar empiricamente a relação entre as universidades e a economia do conhecimento, a UFOB firmou uma parceria com Cyklo Agritech (Aceleradora de Projetos e Startups) no município de Luis Eduardo Magalhães, para a criação de novas empresas na área de pesquisa tecnológica voltada para a agricultura.

A UFRB, através do campus de Cachoeira, tem relação direta com a criação de startups no setor da indústria audiovisual (Sétima.TV). Essa universidade tem um vínculo grande com o setor da economia criativa, pois conta com diversos cursos de graduação na área. Em Cachoeira são oferecidas graduações em: Artes Visuais, Cinema e Audiovisual com Ênfase em Documentário, Comunicação Social Jornalismo, Museologia, Publicidade e Propaganda. No campus da cidade vizinha, em Santo Amaro, os cursos são: Artes do Espetáculo, Música Popular Brasileira, Políticas e Gestão Cultural, Produção Musical, Interdisciplinar em Arte, Interdisciplinar em Cultura, Linguagens e Tecnologias Aplicadas. Além disso, em Cachoeira a universidade tem uma presença forte tanto na Festa Literária Internacional de Cachoeira (Flica) quanto em festivais de cinema (CachoeiraDoc Festival de Documentários de Cachoeira e Festival Internacional de cinema afro). Já a UFOB possui dois cursos no setor criativo, ambos em Santa Maria da Vitória: Artes Visuais, Publicidade e Propaganda.

No tocante a vida cotidiana dessas cidades baianas, a aceitação do novo (novos moradores, novas dinâmicas, novos modos de vida, aumento da diversidade) e das forças externas (influência da universidade) acarreta profundas modificações no cotidiano e nas relações pessoais. Estes processos tornam premente uma mudança na perspectiva de compreensão da rede urbana, com destaque para os novos papéis das cidades, que independente de seu porte ou contingente populacional, passam a contar com formas-conteúdo e com as funções exclusivas e novas, que anteriormente não seriam imaginadas nestas localidades. Constamos modificações no desenho das redes urbanas e nas áreas de influência, cada vez mais complexas e diferenciadas, pois estudantes, professores, funcionários tem origem em diversos estados brasileiros. 
Tanto os planos diretores municipais quanto os planos de criação e implementação dos campi universitários não tratam deste impacto imediato nas cidades. O plano diretor, ainda vigente, de Cachoeira é de 2006, mesmo ano de implementação do Centro de Artes, Humanidades e Letras - CAHL, da UFRB. A falta de planejamento, especialmente no setor de moradia, e o aumento da demanda por habitação leva, primeiramente, a um aumento dos valores dos aluguéis e dos imóveis, uma vez que a oferta e o estoque habitacional nas cidades médias são pequenos.

Algumas empresas, com maior capitalização, passam a construir rapidamente novas moradias, onde se observa uma proliferação daquelas localizadas em condomínios ou loteamentos, irregularmente, fechados, inserido esta nova possibilidade de moradia em muitas cidades (Figura 2). No mercado imobiliário, os desejos e necessidades se espacializam nos condomínios horizontais e verticais, criando espaços de ficções e ilusões, muitas vezes frustradas em relação às representações (propagandas) que foram compradas, mas que continuam a movimentar os egos, as vaidades e os bolsos dos compradores. Muitas empresas buscam desenvolver e construir produtos específicos para este nicho de mercado que é atraído pelas amenidades, localização e possibilidades de financiamento do imóvel. Outro processo perceptível é a transferência da população local, muitas vezes de menor renda, para áreas periféricas, 'liberando' habitações em áreas centrais e de melhor infraestrutura para os novos moradores.

Figura 2 - Anúncio de imóvel associado a UFRB em Cruz das Almas

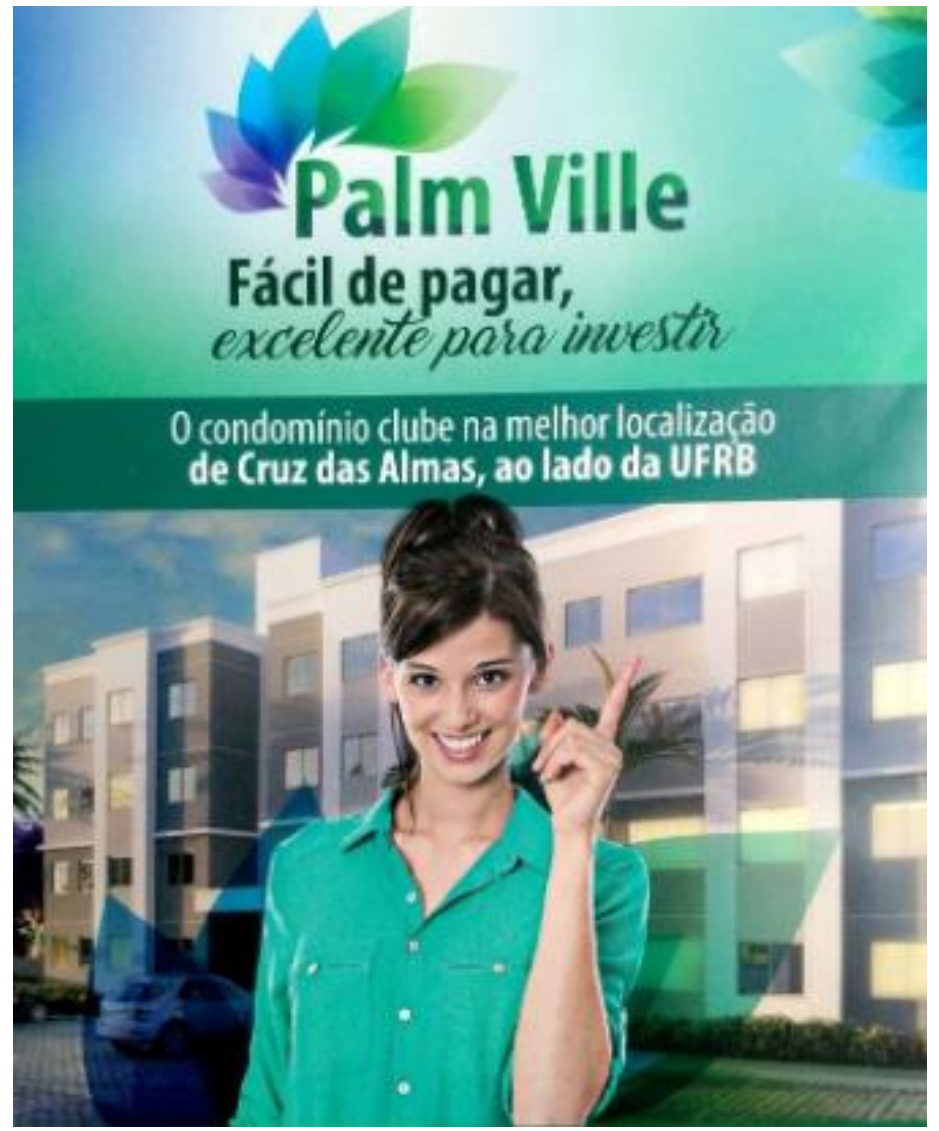

Acervo do autor (2018). 


\subsection{Impactos econômicos}

Os estudos empíricos mais detalhados sobre os impactos econômicos decorrentes da implantação de universidades foram realizados em quatro cidades da Bahia, sedes de campi com ensino presencial da UFRB (Cachoeira, Santo Antônio de Jesus e Cruz das Almas) e mais recentemente da UFOB (Barreiras). A tabela 2 apresenta a população e algumas características de renda e acesso ao saneamento, para ilustrar o perfil da cidade no qual as universidades estão instaladas. Em cidades maiores, como Barreiras ou Santo Antonio de Jesus, o impacto econômico da universidade é diluído com outras atividades dinâmicas, pautadas no agronegócio e comércio, respectivamente. Entretanto, em cidades menores, e naquelas cujas economias estão mais estagnadas ou decadentes, a universidade funcionaria como um impulsionador de desenvolvimento, através, por exemplo do aumento da qualificação profissional e na oferta de empregos formais (Tabela 3), especialmente nos serviços terceirizados.

Tabela 2- Perfil municipal

\begin{tabular}{lcccc}
\hline \multicolumn{1}{c}{ Município } & $\begin{array}{c}\text { População } \\
2020 \\
\text { (estimada) }\end{array}$ & $\begin{array}{c}\text { Pessoas vivendo } \\
\text { com menos de } 1 / 2 \\
\text { salário-mínimo } \\
2010(\%)\end{array}$ & $\begin{array}{c}\text { Pessoas com } \\
\text { empregos } \\
\text { formais } \\
2018(\%)\end{array}$ & $\begin{array}{c}\text { População } \\
\text { com acesso } \\
\text { adequado a } \\
\text { saneamento } \\
2010(\%)\end{array}$ \\
\hline Barreiras & 156.975 & 38,2 & 20,8 & 34.9 \\
Cachoeira & 33.567 & 48,6 & 11,5 & 51.4 \\
$\begin{array}{l}\text { Cruz das Almas } \\
\begin{array}{l}\text { Santo Antonio } \\
\text { de Jesus }\end{array}\end{array}$ & 63.591 & 41,4 & 20,9 & 17.4 \\
\hline
\end{tabular}

Fontes: IBGE - Plataforma Cid@des (2020)

Elaboração: Autor, 2021

Tabela 3 - Evolução do emprego formal de 2005 à 2017

\begin{tabular}{lccccc}
\hline \multicolumn{2}{c}{$\begin{array}{c}\text { Município/ } \\
\text { Ano }\end{array}$} & $\begin{array}{c}\text { Indústria } \\
\text { transformação }\end{array}$ & Comércio & Serviços & $\begin{array}{c}\text { Administra- } \\
\text { ção pública }\end{array}$ \\
\hline Barreiras & 2005 & 821 & 487 & 737 & 707 \\
& 2017 & 2.100 & 8.154 & 9.324 & 4.719 \\
Cachoeira & 2005 & 821 & 487 & 737 & 707 \\
& 2017 & 820 & 606 & 915 & 952 \\
Cruz das & 2005 & 1.930 & 2.579 & 1.317 & 1.561 \\
Almas & 2017 & 1.365 & 3.699 & 3.863 & 1.804 \\
S. Antonio & 2005 & 2.455 & 4.562 & 2.144 & 1.890 \\
de Jesus & 2017 & 4.183 & 7.618 & 5.416 & 2.001 \\
\hline
\end{tabular}

Fonte: SEI/BA. RAIS - Emprego formal na Bahia, relatórios 2005 e 2017. Disponível em https://www.sei.ba.gov.br/; Acesso em 06/03/2021

Além do orçamento direto das instituições, as economias locais recebem grande parcela dos salários dos funcionários técnico-administrativos e professores, sem contar os gastos dos estudantes para manutenção, principalmente quando suas famílias não residem nas cidades. Nas cidades do Recôncavo da Bahia, Santana 
(2012) coloca que o gasto médio dos alunos da UFRB é de aproximadamente $R \$$ 500,00 mensais. Se multiplicarmos este valor médio pelo número de alunos matriculados, temos um investimento direto da ordem de $R \$ 3,1$ milhões para o ano letivo de 2012, nas cidades onde seus campi estão implantados.

Em 2019, o campus de Cruz das Almas possuía 3472 estudantes matriculados (5,45\% da população estimada em 2020), Cachoeira com 1660 estudantes (4,94\% da população) e Santo Antonio de Jesus possuía 930 estudantes matriculados em cursos da área de saúde, entre eles medicina $(0,90 \%$ da população). Tomando como média o gasto mensal indicado por Santana (2012), atualizado pela inflação (50,33\% de acordo com o IBGE) até 2019 (último dado disponível para a UFRB), teríamos um valor de $\mathrm{R} \$ 751,67$, o que traria um potencial de $R \$ 4,5$ milhões ao mês ou $R \$ 54,6$ milhões ao longo do ano. É preciso ressaltar que o valor gasto mensalmente varia de acordo com o curso, com o local de residência (estudantes locais não teriam um extra com pagamento de aluguel) e o valor anual também é impactado pela quantidade de tempo que estudantes passam nas cidades.

Em Barreiras, o dado obtido em nossas pesquisas de campo em 2014, indica um gasto mensal de $R \$ 321,00$. Segundo UFOB (2014), o número de estudantes no campus de Barreiras era de 1338, o que equivaleria a um gasto direto dos alunos de $R \$ 429.498,00$ mensais, ou de $R \$ 3,8$ milhões em um ano letivo de aproximadamente 9 meses. Esses gastos estão voltados para moradia, lazer, transporte e estudos. O setor do comércio relacionado aos itens direto da educação (papelaria, livraria, copiadora) tem uma compreensão mais clara do impacto da UFOB na cidade. Assim como os proprietários/trabalhadores de lan-houses, bares, hotéis, lanchonetes, casas de informática, móveis e eletrodomésticos, que informam uma mudança na clientela após a chegada dos estudantes (jovens) e professores (maior renda), em comparação com o período anterior a instalação do campus.

Os dados mais recentes, indicam que a UFRB (2019) possuía em: Cruz das Almas 495 funcionários técnico-administrativos e 300 professores; Cachoeira contava com 43 funcionários e 123 professores; Santo Antonio de Jesus possuía 61 funcionários e 168 professores. No mesmo ano a UFOB (2019) possuía, em seus cinco campi, 327 docentes, 261 servidores técnico-administrativos e 3.361 estudantes matriculados

Se considerarmos o conjunto de professores, e para fins ilustrativos adotamos como base a prerrogativa de que todos estão em início de carreira e possuem proventos brutos básicos sem adicionais, em torno de $R \$ 10.652,33$ (Classe Assistente 1, 40 horas, Dedicação Exclusiva - tabela de 01/08/2019), temos um impacto potencial mensal na economia dessas cidades de: $\mathrm{R} \$ 38,3$ milhões em Cruz das Almas; $R \$ 15,7$ milhões em Cachoeira; $R \$ 21,4$ milhões em Santo Antonio de Jesus; e $R \$ 41,7$ milhões nas cinco cidades-sede dos campi da UFOB. É evidente que esse número é um potencial estimado, uma vez existem deduções de impostos e previdência e nem todo os recursos salariais se configuram em disponibilidade para consumo direto.

Como já mencionado, os professores universitários, devido a sua qualificação, possuem, em algumas cidades médias, uma renda mensal média muito superior à da população local, acabam acarretando uma supervalorização de alguns espaços

Para0nde!?, Porto Alegre, v.15, n.1, p.35-56, 2021. http://seer.ufrgs.br/paraonde 
internos específicos da cidade, não só em função do nível de renda maior, mas também do perfil de consumo que se estabelece. Os professores, segundo dados da pesquisa de campo, gastam a maior parte dos seus vencimentos com moradia, sendo que a maioria se muda para a nova cidade sozinhos. No caso de Barreiras, esses professores informam que a cidade é mais cara que seus municípios de origem, sendo o aluguel apontado como muito elevado especialmente para uma cidade do porte de Barreiras, com tão pouca oferta de serviços. Outro grupo de professores opta por permanecer na cidade nova apenas uma parte da semana, mesmo com distâncias consideráveis de seu lugar de residência. Esse grupo que faz deslocamentos semanais afirma que muitas cidades que receberam os novos campi não possuem atrativos de lazer ou infraestrutura para justificar uma mudança completa das suas residências. $\mathrm{Na}$ Bahia, alguns relatam deslocamentos semanais entre Vitória da Conquista ou Barreiras até Salvador.

De maneira geral, todos os entrevistados nas diversas cidades médias da Bahia que receberam campi universitários na última década reconhecem a importância da política de expansão, da melhoria do acesso ao ensino superior no estado, mas também apontam problemas, tanto na infraestrutura física e tecnológica dos campi, quanto nas cidades. No que se refere as cidades, tais como falta de infraestrutura em geral (internet, saneamento, pavimentação, transporte), serviços melhores na área de saúde (hospitais, médicos, dentistas), equipamentos de compra e serviços (shopping-centers) e, em muitos casos, a completa falta de equipamentos culturais, tais como teatros, cinemas, livrarias ou espaços para shows.

Segundo uma matéria vinculada pelo Jornal A Tarde (Gomes, 2010), a UFRB, desde sua implementação, vinha movimentando a economia das cidades do Recôncavo, com impacto muito perceptível no mercado de locação dos imóveis. Nesta reportagem, o jornalista destaca como muitos moradores estão investindo na melhoria de suas casas, comprando móveis novos, para atrair entre os estudantes possíveis locatários de imóveis ou quartos e poder 'tirar proveito' da presença da universidade (Figura 3). Uma das entrevistadas, por exemplo, afirmou que só reconheceu uma movimentação semelhante a esta provocada pela universidade na cidade de Cachoeira, quando houve a construção da Barragem de Pedra do Cavalo, na década de 1980. Contudo para ela, atualmente a expectativa de obter ganhos o aluguel de quartos para os estudantes da UFRB.

As indústrias, lojas, bancos, diversos comércios ou serviços são implantados, construídos e podem mudar ou abandonar cidades após um tempo. Entretanto, dificilmente uma universidade deixa uma cidade. Dessa forma, a perspectiva de desenvolvimento econômico é mais estável e garantida em longo prazo. É importante destacar que o processo de expansão das universidades federais é muito recente. Muitas questões problemáticas, no tocante as cidades, ainda estão em fase embrionária de resolução, mas a perspectiva é que a oferta de infraestrutura e serviços melhore e se adapte as novas funções e perfil de moradores dessas cidades. 
Figura 3 - Imóvel com quartos para estudantes em Cachoeira

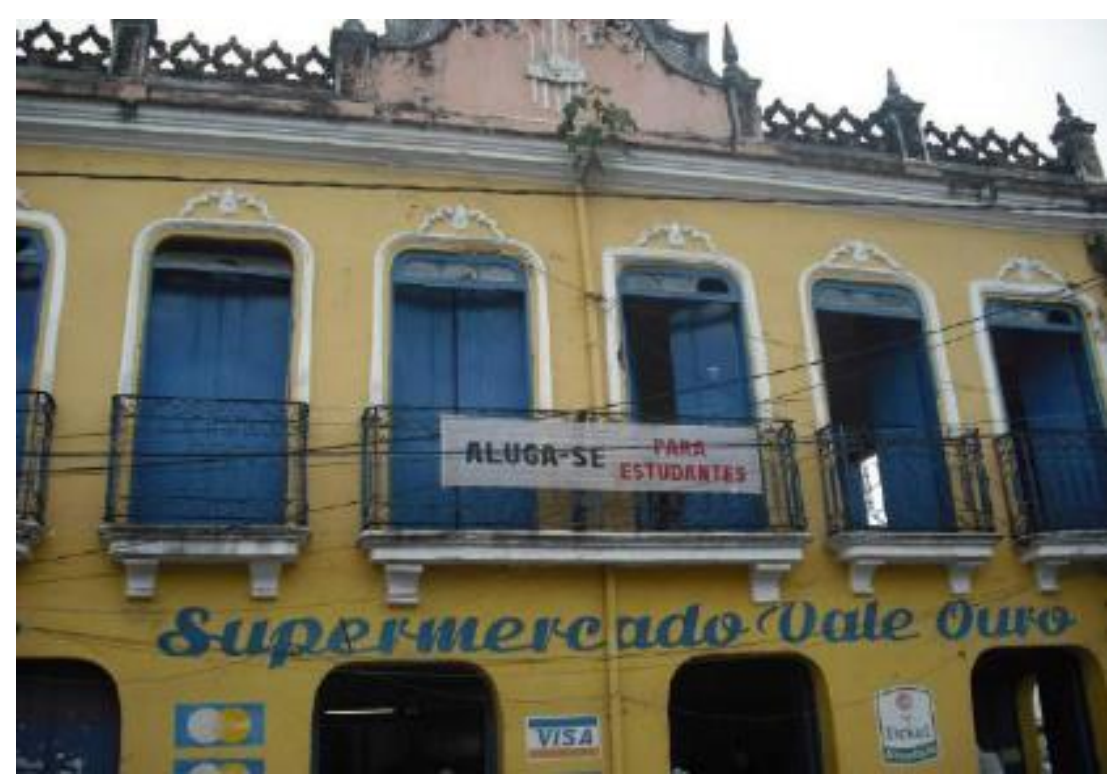

Acervo do autor (2012).

\section{Considerações Finais}

Reafirmamos a importância de se pesquisar também o caráter econômico da instalação dos novos campi universitários, inclusive porque essas novas universidades e campi tiveram como justificava de criação/instalação a promoção do desenvolvimento econômico urbano e regional. Essa característica desenvolvimentista aparece nos documentos de criação e/ou de direcionamento das suas ações. O caráter espacial/territorial da política pública de instalação dos campi universitários coaduna com as ideias de vinculação das cidades universitárias a uma proposta de economia do conhecimento e cidade inovadora. O estudo geográfico da associação da universidade com as startups, por exemplo, é um caminho de pesquisa ainda em aberto.

Observamos que as relações que se estabelecem entre a população local e a comunidade acadêmica, em muitos casos, são relações conflituosas, instigadas, notadamente, pelos estilos de vida dissonantes, quer seja pelo padrão de consumo dos professores, pelas festas estudantis ou pelas crenças políticas da população local. Esta questão torna-se um elemento central no processo de consolidação da universidade/campus como algo que faz parte da cidade. Entretanto, estudos preliminares para as cidades médias e pequenas indicam um forte distanciamento entre a cidade e a universidade, mesmo que espacialmente ele não seja considerável, pois os grupos tendem a vivenciar espaços quase que pré-definidos pelo tipo/origem de usuário, 'evitando' os encontros entre os grupos de moradores e os acadêmicos.

Apesar desse estranhamento inicial, diversos eventos culturais tais como peças de teatro, shows de música, festas literárias e, principalmente, congressos científicos, passaram a ocorrer nessas cidades. Muitos desses eventos têm caráter 
internacional e acabam por atrair visitantes estrangeiros, projetando outra imagem das cidades, agora internacionalmente.

Por fim, cabem algumas perguntas que podem fundamentar os futuros estudos sobre essa temática: Para onde vai a geografia das universidades federais? O que essa nova década que se inicia trará para a expansão, ou melhor, manutenção do Sistema Federal de Ensino Superior? Qual o impacto da covid-19 na dinâmica intraurbana das cidades universitárias?

Em relação a pandemia do covid-19, podemos inferir que a passagem maciça do ensino presencial para o online nas Universidade Federais, em razão das medidas necessárias de segurança sanitária, causou um imenso impacto econômico no setor de comércio e serviços das cidades sede dos campi. A ausência física da comunidade acadêmica, em especial, estudantil, retirou de circulação de Cruz das Almas/BA, por exemplo, um gasto médio mensal de $R \$ 751,67$ (valores estimados corrigidos pela inflação) por estudante, para alimentação e moradia. Muitos estudantes retornaram para as casas dos familiares durante esse período, diminuindo a procura por imóveis. Novas pesquisas podem aprofundar esse estudo econômico, bem como avaliar as dimensões pedagógicas e psicológicas que perpassam as rodas de discussão online da comunidade universitária.

São questões amplas, que decorrem de discussões sobre o direcionamento das políticas públicas que serão adotadas no país. O que podemos identificar, é que os 10 últimos anos, que separam 2010 de 2020, nos colocam em uma perspectiva totalmente diferente em relação ao futuro das Universidades Federais. Esse futuro poderá ser estudado através das leituras dessas novas políticas; análises dos novos orçamentos destinados às universidades; pesquisas sobre as percepções da comunidade acadêmica; e levantamento de dados disponibilizados pelos diversos órgãos oficiais que mapeiam e produzem estatísticas sobre a educação superior.

\section{Referências}

BAUMGARTNER, Wendel Henrique. Small city and new University. Perspectives and conflicts after the establishment of new public Brazilian universities in small cities. In: COLLOQUE AUX FRONTIĖRES DE L'URBAIN. PETITES VILLES DU MONDE: émergence, croissance, rôle économique et social, intégration territoriale, gouvernance. 22 a 24 de Janeiro de 2014, Avignon. Anais. Avignon: Université d'Avignon, 2014. p. $759-775$.

BAUMGARTNER, Wendel Henrique. Cidades Universitárias, Cidades Médias, Cidades Pequenas: Análises sobre o processo de instalação de novos campi universitários. Espaço Aberto, Rio de Janeiro, vol.5, n.1, p. 73-93, 2015a.

BAUMGARTNER, Wendel Henrique. Universidades públicas como agentes de desenvolvimento urbano e regional de cidades médias e pequenas: uma discussão teórica, metodológica e empírica. Geotextos (Salvador), vol. 11, n.1, p. 91-111, 2015b.

BAUMGARTNER, Wendel Henrique \& ROTHFUSS, Ebehard. Creative Inequality in the Mid-sized University City. Socio-spatial Reflections on the Brazilian Rural-Urban Interface: The Case of Cachoeira In: GERHARD, Ulrike; HOELSCHER, Michael; 
WILSON, David. Inequalities in Creative Cities. London: Palgrave Macmillan, 2017, p. 217-237.

BAUMGARTNER, Wendel Henrique. Novas cidades universitárias e desenvolvimento urbano e econômico. In: BRANDÃO, Paulo Roberto Baqueiro (Org.). Cidades Médias e Pequenas: Reflexões sobre Dinâmicas Espaciais Contemporâneas. Curitiba: Appris, 2019, p. 130-151.

BRASIL (Presidência da República). Decreto № 6.096, de 24 de abril de 2007. Disponível em: http://www.planalto.gov.br/ccivil_03/_Ato20072010/2007/Decreto/D6096.htm; Acessado em 28/12/2020.

CAPEL, Horácio. La Morfología de las Ciudades. Vol.I - Sociedad, cultura y paisaje urbano. Barcelona: Ediciones del Serbal, 2002. 544p.

CASSIOLATO, José Eduardo. A Economia do Conhecimento e as Novas Políticas Industriais e Tecnológicas. In: LASTRES, H. M. M \& ALBAGLI, Sarita (Org.). Informação e globalização na era do conhecimento. Rio de Janeiro: Campus, 1999, p. 164-190.

CLAVAL, Paul. Politics and the university. In WUSTEN, Herman van der (Ed.). The urban university and its identity. Roots, locations, roles. Dordrecht: Kluwer Academic Publishers, 1998, p.29-46.

DEMAZIERE, C.; BAUMGARTNER, Wendel Henrique. Les universités dans les petites et moyennes villes au Brésil et en France: mise en place et effets In: Vivre le territoire et faire la ville autrement ? Regards croisés franco-brésiliens. Lille: Presses Universitaires du Septentrion, 2017, v.01, p. 70-95.

FLORIDA, Richard. The rise of creative class. New York: Basic Books, 2002. 512p.

FLORIDA, Richard. Cities and creative class. New York: Routledge, 2005. 464p.

FLORIDA, R.; MELLANDER, C.; KING, K. The global creativity index 2015. Toronto: Martin Prosperity Institute/Rotman, 2015.

GOMES, Donaldson. UFRB movimenta economia do território. Jornal A Tarde, 13/09/2010.

https://atarde.uol.com.br/politica/eleicoes/noticias/1297608-ufrb-movimenta-

economia-do-territorio; Acessado em 06/03/2021.

HENRIQUE, Wendel. A instalação da UFRB, a ação do Programa Monumenta e o turismo étnico na reestruturação urbana e no cotidiano de Cachoeira-BA: Notas preliminares de pesquisa. Geotextos (Salvador), vol.5, n.1, p. 89-112, julho/2009.

HENRIQUE, Wendel. Dinâmicas urbanas e regionais em cidades médias após a instalação de universidades públicas. In: SEMINÁRIO DA REDE IBEROAMERICANA DE PESQUISADORES SOBRE GLOBALIZAÇÃO E TERRITÓRIO, XII, 01-04/10/2012, Belo Horizonte. Anais do XII Seminário da RII, 2012. v. 01. p. 01-16.

HENRIQUE, Wendel. Serviços educacionais, expansão de universidades públicas e o desenvolvimento urbano e regional de cidades médias e pequenas no Brasil. In: GUTIÉREZ, J.A et al. (Org.). Los Servicios: dinámicas, infraestructuras y cohesión territorial. Cáceres: Copergraf S.L., 2013, v. 01, p. 197-209. 
PNUD (Programa das Nações Unidas para o Desenvolvimento). Atlas do Desenvolvimento Humano no Brasil. Perfil municipal de Cachoeira/BA. Brasília: PNUD, 2013.

SANTANA, Elissandro Trindade de. A Universidade Federal do Recôncavo da Bahia e a Produção do Espaço Urbano-Regional. 1 vol. Dissertação (Mestrado em Geografia). Universidade Federal da Bahia, Salvador, 2012.

SANTOS, Milton. A natureza do espaço. Tempo-espaço razão-emoção. São Paulo: Hucitec, 1997. 260p.

SANTOS, Milton. A urbanização brasileira. São Paulo: Edusp, 2005. 176p.

SPOSITO, Maria Encarnação Beltrão. O chão em pedaços: urbanização, economia e cidades no Estado de São Paulo. Tese (Livre Docência). UNESP, Presidente Prudente, 2004.

UFOB (Universidade Federal do Oeste da Bahia). Relatório de gestão 2014. Barreiras: UFOB, 2015. Disponível em Disponível em https://acessoainformacao.ufob.edu.br/index.php/transparencia-e-prestacao-decontas; Acesso em 10/08/2015.

UFOB (Universidade Federal do Oeste da Bahia). Relatório de gestão 2019. Barreiras: $\quad 2019 . \quad$ UFOB, Disponível em https://acessoainformacao.ufob.edu.br/index.php/transparencia-e-prestacao-decontas; Acesso em 06/03/2021.

UFRB (Universidade Federal do Recôncavo da Bahia). Relatório de gestão, 2019. Disponível em: https://www.ufrb.edu.br/proplan/relatorios-de-gestao; Acesso em: 06/03/2021.

ZECHER, Sara. The Economic Role of Universities in Medium-Sized Cities: A Case Study of the Medical College of Georgia in Augusta, Georgia. 1vol. Dissertação (Mestrado em Políticas Públicas). Georgia Institute of Technology, 2005.

WIPO/ONU (World International Property Organization). Global Innovation Index 2011; Geneva: WIPO, 2011.

WIPO/ONU (World International Property Organization). Global Innovation Index 2019; Geneva: WIPO, 2019.

WUSTEN, Herman van der. A warehouse of precious goods. The university in its urban context. In: WUSTEN, Herman van der (Edt.). The urban university and its identity. Roots, locations, roles. Dordrecht: Kluwer Academic Publishers, 1998, p.113. 